сельскохозяйственных культур как для экономики региона, так и для страны в целом. Одним из способов повышения урожайности выступает защита растений от болезней посредством использования фунгицидов. Исследования были проведены на основе результатов проекта «БайАрена» компании АО «Байер» для культур, произрастающих на территории Краснодарского края. В рамках данного проекта специалистами компании проводится демонстрация высокоэффективных технологий в области защиты культурных растений. Были собраны основные зна- чения показателей в результате использования различных комплексов фунгицидной защиты, с помощью метода интегральной оценки составлена характеристика каждого способа защиты, приведены результаты интегральной оценки подобных средств на примере продукции компании АО «Байер» и составлена характеристика наиболее эффективного средства защиты для пшеницы озимой и ячменя озимого. Выявлен наиболее значимый параметр по группе, который в большей мере влияет на результат интегральной оценки.

D. Obozova, S. Kosnikov

\title{
INTEGRAL ASSESSMENT OF FUNGICIDES AS AN EFFECTIVE MEANS OF PROTECTION OF AGRICULTURAL CROPS
}

\author{
Key words: fungicides; remedy; crops; efficiency; integral assessment.
}

\section{Authors' personal details}

1. Obozova Diana, student of the Faculty of Applied Informatics, Kuban State Agrarian University named after I.T. Trubilin, Krasnodar, Kalinina str., 13, e-mail: obozova.99@mail.ru.

2. Kosnikov Sergey, associate professor of the Department of Economic Cybernetics, Kuban State Agrarian University named after I.T. Trubilin, Krasnodar, Kalinina str., 13.

The rapid development of agricultural technologies contributes to the emergence of modern means of effective biological and chemical plant protection. Thanks to such tools, a noticeable increase in productivity is observed. However, in this case, the result can be affected by many factors, for example, weather conditions, quality of soil, varieties and many others. The article discusses the topic of chemical means of protection of cultivated plants, namely winter wheat and winter barley. The importance of increasing crop yields both for the economy of the region and for the country as a whole is noted. One of the ways to increase productivity is to protect plants from diseases through the use of fungicides. The studies were conducted based on the results of the BayAren project of Bayer JSC for crops growing in the Krasnodar Territory. Within the framework of this project, the company's specialists are demonstrating highly effective technologies used by the company in the field of crop protection. The main values of the indicators were collected as a result of using various complexes of fungicidal protection, using the integral assessment method. The characteristics of each protection method were compiled, the results of an integrated evaluation of similar products were compiled using Bayer products as an example, and the most effective protective product for winter wheat and barley was found. The most significant parameter in the group was revealed, which to a greater extent affects the result of the integral assessment.

( С Обозова Д.О., Косников С.Н.

УДК 634.1/7:631.53.03

DOI: 10.31563/1684-7628-2020-53-1-39-44

Л.В. Уфимцева, Н.В. Глаз

\section{СОВЕРШЕНСТВОВАНИЕ ЭЛЕМЕНТОВ ТЕХНОЛОГИИ ПРОИЗВОДСТВА САЖЕНЦЕВ ГРУШИ В КОНТЕЙНЕРАХ}

\section{Ключевые слова: почвогрунт; груша; торф; гидрогель; удобрение пролонгированного действия.}

Введение. Традиции размножения садовых растений в контейнерах уходят корнями вглубь веков. Бурное развитие «контейнерной культуры» получило во второй половине двадцатого 
столетия на фоне интенсификации садоводства, развития принципиально новых направлений в ландшафтном дизайне [1]. В настоящее время в садоводстве и зеленом благоустройстве все шире используется технология выращивания саженцев с закрытой корневой системой в малообъемных контейнерах. При этом существенно возрастает временной интервал для реализации и высадки саженцев в открытый грунт, облегчается уход, повышается количество получаемых саженцев с единицы площади, а также улучшается сохранность саженцев в период хранения и реализации [2-4]. При выращивании посадочного материала с закрытой корневой системой наряду со свойствами плодородия большую роль играет технологичность грунтов, их стерильность и свобода от семян сорных растений [5-6]. Для получения качественного посадочного материала плодово-ягодных и декоративных культур с использованием малообъемных контейнеров большое значение имеет подбор оптимального соотношения компонентов почвогрунтов, длительное время обеспечивающих растения питательными элементами, влагой и кислородом. Создание благоприятного водновоздушного режима в условиях ограниченного объема посадочного контейнера является определяющим при выращивании саженцев с закрытой корневой системой. Для предотвращения уплотнения грунта используются такие компоненты почвенного скелета, как керамзит, вермикулит и крупный песок. В качестве влагоемкого компонента используются верховой торф малой минерализации и различные агрогели [7-8]. Важным компонентом почвогрунта является удобрение пролонгированного действия [5].

Цель исследований - совершенствование состава почвогрунта как элемента технологии производства саженцев груши при выращивании их в малообъемных контейнерах.

Условия, материалы и методы. Исследования проведены в 2016-2018 гг. в ЮжноУральском научно-исследовательском институте садоводства и картофелеводства - филиале ФГБНУ «Уральский федеральный аграрный научно-исследовательский центр УрО РАН» в рамках выполнения государственного задания по теме «Теория и принципы разработки и формирования технологий возделывания экономически значимых сельскохозяйственных культур в целях конструирования высокопродуктивных агрофитоценозов и агроэкосистем». Объектом исследований служили саженцы районированного на Урале летнего сорта груши челябинской селекции - Красуля. Саженцы были получены способом зимней прививки способом «улучшенная копулировка». Гидрогель «Аквасин» был предоставлен для опыта ООО «Сингер» в рамках договора о сотрудничестве и изучался нами в 2017 и 2018 гг.

Опыты закладывали в трехкратной повторности по 15 растений в каждом варианте. Высадка растений производилась в контейнеры из полиэтилена объемом 1 литр.

Удобрение длительного действия Basacote $6 \mathrm{M}$ в своем составе содержит: $16 \%$ азота $(\mathrm{N})$, $8 \%$ фосфора $\left(\mathrm{P}_{2} \mathrm{O}_{5}\right), 12 \%$ калия $\left(\mathrm{K}_{2} \mathrm{O}\right), 2 \%$ магния $(\mathrm{MgO}), 5$ \% серы $(\mathrm{S})$, а также микроэлементы в хелатной форме: бор (B) - 0,02 \%, медь $(\mathrm{Cu})-0,05 \%$, железо $(\mathrm{Fe})-0,4 \%$, марганец $(\mathrm{Mn})$ $-0,06 \%$, молибден (Mo) - 0,015\% и цинк $(\mathrm{Zn})-$ $0,02 \%$. Данное удобрение имеет государственную сертификацию на территории Российской Федерации (свидетельство от 20.02.2013 г. № 2526) $[9,10]$. Изучаемая норма внесения в почвосмесь составляла $0,5 \%$.

При приготовлении почвогрунта в качестве влагоемкого органического наполнителя использовался переходный торф фракции измельчения от 0 до 20 мм. Гидрогель марки «Аквасин», разработанный отечественными учеными, изучался в качестве регулятора водоудерживающей способности и для улучшения физических свойств комбинируемых почвосмесей [11].

В течение вегетационного периода и перед посадкой в соответствии с ГОСТ 27753.2-88 в почвогрунтах определялись ионометрически $\mathrm{pH}$ водной вытяжки, по ГОСТ 27753.6-88 определяли содержание водорастворимого калия ионометрически, фотометрически с реактивом Гетри (экстрагент этанол), содержание хлорофилла $(\mathrm{a}+\mathrm{b})$ по ГОСТ 27753.5-88, определялось содержание водорастворимого фосфора, по ГОСТ 27753.8-88 фотометрически с реактивом Несслера - содержание аммонийного азота, по ГОСТ 27753.7-88 ионометрически содержание нитратного азота, по ГОСТ Р 53135-2008 на основе биометрических показателей длины вегетативного прироста и диаметра штамба оценивалась товарность полученных саженцев [12]. Технология ухода за саженцами выполнялась по общепринятой схеме в биоклиматических условиях северной лесостепи Южного Зауралья.

Схема опыта. 1. Почва и торф переходный в соотношении $4: 1$ (базовая смесь, контроль); 2. Базовая смесь + Базакот 6 M (5 г/л); 3. Базовая смесь + Базакот 6 М (5 г/л) + Гидрогель (1 г/л); 4. Базовая смесь + Гидрогель (1 г/л); 5. Почва, перегной и торф в соотношении 2,5:1,5:1; 6. Почва, перегной и торф (в соотношении $2,5: 1,5: 1)+$ Базакот 6 M (5 г/л).

Результаты исследований и их обсуждение. Чернозем выщелоченный, используемый для приготовления почвогрунтов, характеризо- 
вался следующими показателями: $\mathrm{pH}$ солевой вытяжки - 5,5, содержание подвижного фосфора - 56,5 мг/кг, обменного калия - 201 мг/кг, обменного аммония - 46,1 мг/кг, нитратного азота - 11,0 мг/кг почвы.

Почвогрунты в вариантах опыта характеризовались слабокислой реакцией почвенного раствора. На контроле (базовая смесь) содержание минерального азота составило 73,6 мг/кг. Добавление в состав почвогрунта гидрогеля увеличивало этот показатель несущественно (до 75,5 мг/кг), а удобрения пролонгированного действия - на 83 \% (135,7 мг/кг). Наибольшее содержание водорастворимого фосфора и калия отмечалось в варианте совместного применения Базакота и гидрогеля - 34,6 и 56,7 мг/кг (контроль - 22,1 и 33,3 мг/кг соответственно).

Состав почвенной смеси оказывал существенное влияние на характер биометрических показателей развития и фотосинтетической активности листового аппарата саженцев груши (таблица 1).

Введение перегноя в состав почвогрунта в 2016 г. не обеспечило повышение качества посадочного материала, в связи с этим в последующие годы исследований данный компонент не испытывался. Оптимальным для выращивания саженцев груши с закрытой корневой системой оказался вариант почвогрунта почва + торф
$(4: 1)+$ Базакот (5 г/л). В среднем за 3 года исследований внесение удобрения пролонгированного действия увеличивало длину вегетативного прироста саженцев груши на 36,4 \%, площадь листьев - на 51,1 \%, диаметра штамба - на 52,2 \% по сравнению с контролем. Сбалансированный комплекс элементов питания обеспечил повышение концентрации хлорофилла $(\mathrm{a}+\mathrm{b})$ в листьях в среднем на 21,4 \%. Исследования показали, что введение в состав почвосмеси гидрогеля не имело положительного эффекта по сравнению с оптимальным вариантом (почва + торф в соотношении $4: 1+$ Базакот, 5 г/л). По нашему мнению, использование гидрогеля для улучшения влагоемкости оправдано только в случае выраженной периодичности полива. Тогда как в условиях стабильной влагообеспеченности в течение вегетационного периода применение гидрогеля нецелесообразно.

В таблице 2 приведено распределение саженцев груши по высоте в условиях 2018 году. В 2017 г., а также в 2016 г. по первому и второму вариантам характер распределения саженцев был аналогичным.

Рентабельность производства посадочного материала определяется выходом саженцев первого и второго товарных сортов в течение вегетационного периода (таблица 3).

Таблица 1 Развитие саженцев груши на различных составах почвосмесей в малообъемных контейнерах

\begin{tabular}{|c|c|c|c|c|}
\hline Вариант опыта & $\begin{array}{c}\text { Площадь } \\
\text { листьев, } \text { см }^{2} \\
\end{array}$ & $\begin{array}{c}\text { Длина } \\
\text { прироста, см } \\
\end{array}$ & $\begin{array}{c}\text { Диаметр } \\
\text { штамба, мм }\end{array}$ & $\begin{array}{l}\text { Содержание хлоро- } \\
\text { филла в листьях, \% }\end{array}$ \\
\hline \multicolumn{5}{|c|}{2016 г. } \\
\hline Почва + торф (4 : 1) & 13,24 & 44,0 & 4,0 & 1,53 \\
\hline Почва + торф (4 : 1) + Базакот (5 г/л) & 28,33 & 66,6 & 5,4 & 1,65 \\
\hline Почва + торф + перегной $(2,5: 1,5: 1)$ & 16,9 & 48,8 & 5,0 & 1,62 \\
\hline Почва + торф + перегной $(2,5: 1,5: 1)+$ Базакот (5 г/л) & 22,9 & 63,5 & 6,3 & 1,60 \\
\hline $\mathrm{HCP}_{05}$ & 5,15 & 4,6 & 0,4 & 0,02 \\
\hline \multicolumn{5}{|c|}{2017 г. } \\
\hline Почва + торф (4 : 1) & 27,78 & 63,0 & 5,1 & 1,74 \\
\hline Почва + торф (4 : 1) + Базакот (5 г/л) & 34,52 & 90,0 & 8,1 & 2,16 \\
\hline Почва + торф (4 : 1) + Гидрогель (1 г/л) & 34,03 & 90,0 & 8,1 & 1,90 \\
\hline Почва + торф (4 : 1) + Базакот (5 г/л) + Гидрогель (1 г/л) & 35,71 & 81,0 & 7,2 & 2,19 \\
\hline $\mathrm{HCP}_{05}$ & 4,78 & 7,2 & 0,5 & 0,05 \\
\hline \multicolumn{5}{|c|}{2018 г. } \\
\hline Почва + торф (4:1) & 27,4 & 76,3 & 4,7 & 1,69 \\
\hline Почва + торф (4 : 1) + Базакот (5 г/л) & 40,5 & 93,5 & 7,5 & 2,21 \\
\hline Почва + торф (4 : 1) + Гидрогель (1 г/л) & 34,5 & 85,0 & 7,7 & 1,85 \\
\hline Почва + торф (4 : 1) + Базакот (5 г/л) + Гидрогель (1 г/л) & 38,9 & 75,8 & 4,6 & 2,11 \\
\hline $\mathrm{HCP}_{05}$ & 2,8 & 7,9 & 0,47 & 0,16 \\
\hline
\end{tabular}

Таблица 2 Распределение саженцев с закрытой корневой системой по вегетативному приросту, \% (2018 г.)

\begin{tabular}{|l|c|c|c|c|c|}
\hline \multirow{2}{*}{ Вариант опыта } & \multicolumn{5}{|c|}{ Длина вегетативного прироста, см } \\
\cline { 2 - 6 } & $0-19$ & $20-39$ & $40-59$ & $60-79$ & $\geq 80$ \\
\hline Почва + торф $(4: 1)$ & 6,4 & 29,8 & 42,5 & 17,0 & 4,3 \\
\hline Почва + торф (4:1)+ Базакот (5 г/л) & 4,6 & 25,6 & 16,3 & 39,5 & 14,0 \\
\hline Почва + торф (4:1)+ Гидрогель (1 г/л) & 4,6 & 23,2 & 27,9 & 23,2 & 21,1 \\
\hline Почва + торф (4:1) + Базакот (5 г/л)+ Гидрогель (1 г/л) & 10,5 & 38,5 & 26,0 & 21,0 & 4,0 \\
\hline
\end{tabular}


Таблица 3 Выход стандартных саженцев груши, \%

\begin{tabular}{|l|c|c|c|c|}
\hline \multirow{2}{*}{ Вариант опыта } & \multicolumn{3}{c|}{ Доля саженцев 1 и 2 товарных сортов, \% } \\
\cline { 2 - 5 } & 2016 г. & 2017 г. & 2018 г. & Среднее \\
\hline Почва + торф $(4: 1)$ & 7,8 & 23,3 & 21,3 & $\mathbf{1 7 , 5}$ \\
\hline Почва + торф $(4: 1)+$ Базакот (5 г/л) & 48,5 & 66,8 & 53,5 & $\mathbf{5 6 , 3}$ \\
\hline Почва + торф (4:1)+ Гидрогель (1 г/л) & - & 44,8 & 44,3 & $\mathbf{4 4 , 6}$ \\
\hline Почва + торф $(4: 1)+$ Базакот $(5$ г/л) + Гидрогель (1 г/л) & - & 72,7 & 25,0 & $\mathbf{4 8 , 9}$ \\
\hline Почва + торф + перегной $(2,5: 1,5: 1)$ & 3,0 & - & - & $\mathbf{3 , 0}$ \\
\hline Почва + торф + перегной $(2,5: 1,5: 1)+$ Базакот (5 г/л) & 35,3 & - & - & $\mathbf{3 5 , 3}$ \\
\hline
\end{tabular}

Примечание. Варианты с перегноем в 2017 и 2018 гг., а с гидрогелем в 2016 г. не изучались.

В варианте использования почвосмеси с добавлением удобрения Базакот отмечено повышение товарности (то есть пригодности саженцев к реализации в первый год выращивания) в среднем до $56,3 \%$, что в 3,2 раза больше, чем на контроле. Применение гидрогеля Аквасин обеспечивало двукратное увеличение выхода товарных саженцев груши по сравнению с контролем (в среднем за 2017-2018 гг.) - с 22,3 до 44,6 \%. Совместное использование Базакота и гидрогеля в составе почвогрунта для выращивания саженцев груши достоверно повышало долю товарных саженцев по сравнению с применением одного Базакота только в условиях 2017 года (с 66,8 до 72,7 \%). Оценка экономической эффективности использования изучаемых компонентов почвогрунта при выращивании саженцев груши с закрытой корневой системой показало, что максимальную рентабельность в условиях 2018 года обеспечило применение удобрения пролонгированного действия Базакот $6 \mathrm{M}$ в качестве стабилизатора минерального питания. Рентабельность производства саженцев в этом варианте составила $103 \%$. Для сравнения в варианте совместного использования удобрения Базакот $6 \mathrm{M}$ и гидрогеля Аквасин это показатель составил $65 \%$, а в варианте применения базовой смеси производство саженцев в условиях 2018 г. был нерентабельным.

Выводы. Применение удобрения пролонгированного действия Базакот марки $6 \mathrm{M}$ в составе почвогрунта при выращивании саженцев груши с закрытой корневой системой в малообъемных контейнерах оказывает положительное влияние на рост и развития саженцев груши, увеличивая длину вегетативного прироста в среднем на $36,4 \%$, площадь листьев - на 51,1 \%, диаметр штамба - на 52,2 \% по сравнению с контролем. Выход товарных саженцев по сравнению с вариантом использования базовой смеси (почва + торф в соотношении $4: 1$ ) при этом увеличивался в 3,2 раза. Рентабельность производства саженцев в этом варианте в условиях 2018 года составила $103 \%$. Использование гидрогеля для улучшения влагоемкости почвогрунтов обеспечивало двукратное увеличение выхода товарных саженцев груши по сравнению с контролем (в среднем за 2017-2018 гг.) - с 22,3 до 44,6 \%.

\section{Библиографический список}

1. Куликов, И.М. Основные направления инновационного развития садоводства и питомниководства в России [Текст] / И.М. Куликов, В.Ф. Воробьев, В.В. Хроменко, С.Н. Коновалов, Г.И. Кадыкало, А.Ю. Павлова, Н.Ю. Джура, А.В. Лисина, В.Г. Селиванов. М., 2017. 132 с.

2. Цепляев, А.Н. Опыт выращивания посадочного материала с ЗКС по системе «Горшок в горшке» (РОT-IN-POT) [Текст] / А.Н. Цепляев // Развитие идей Г.Ф. Морозова при переходе к устойчивому лесоуправлению: материалы международной научно-технической юбилейной конференции. Воронеж, 2017. С. 242-244.

3. Цепляев, А.Н. Особенности контейнерного выращивания растений в условиях Центрально-Черноземного региона [Текст] / А.Н. Цепляев // Питомники России: инновации и импортозамещение. Сборник докладов IX ежегодной конференции Ассоциации производителей посадочного материала. М.: АППМ, 2016. C. 67-70.
4. Раджабов, А.А. Разработка элементов технологии выращивания саженцев яблони в контейнерах [Текст] / А.А. Раджабов, А.А. Никитенко // Плодоводство и ягодоводство России. 2017. T. 51. C. 216-222.

5. Глаз, Н.В. Перспективы применения удобрения пролонгируемого действия Basacote при выращивании посадочного материала в контейнерах [Текст] / Н.В. Глаз, Л.В. Уфимцева // Агрохимический вестник. 2018. № 3. С. 12-14.

6. Никитенко, А.А. Влияние состава субстрата на содержание основных питательных элементов в листьях побегов яблони [Текст] / А.А. Никитенко // Плодоводство и ягодоводство России. 2017. Т. 48. № 2. С. 213-216.

7. Уфимцева, Л.В. Применение гидрогеля при выращивании саженцев в контейнерах [Текст] / Л.В. Уфимцева, Н.В. Глаз, А.С. Мелихова // Ученые заметки ТОГУ. 2018. Т. 9. № 2. C. 746-752. 
8. Васильев, А.А. Влияние глауконита на минеральное питание растений картофеля [Текст] / А.А. Васильев // Вестник Башкирского государственного аграрного университета. 2014. № 3 (31). C. 17-20.

9. Trenkel M.E. Slow- and controlled-release and stabilized fertilizers: an option for enhancing nutrient use efficiency in agriculture. Paris: IFA, 2010. $160 \mathrm{p}$.

10. Сертификаты на удобрения СОМРО [Электронный ресурс]. Режим доступа: https:// www.agbina-compo.ru/info/613 (дата обращения 03.08.2018).
11. Гидрогель [Электронный ресурс]. Режим доступа: https://www.tdsinger.ru (дата обращения 03.08.2018).

12. Куликов, И.М. Инновационные технологии возделывания плодовых и ягодных культур [Текст]: методические рекомендации / И.М. Куликов, В.Ф. Воробьев, С.Е. Головин, В.В. Хроменко, А.Ю. Павлова, Н.Ю. Джура, Е.А. Туть, В.А. Шевкун, С.Н. Коновалов, Г.И. Кадыкало, А.В. Лисина, О.Г. Грибоедова, В.Ф. Федоренко, В.Г. Селиванов, С.Н. Юдина. М., 2016. 228 с.

\title{
Сведения об авторах
}

1. Уфимцева Лариса Викторовна, кандидат биологических наук, заведующий лабораторией инструментальных методов исследования, Уральский федеральный аграрный научно-исследовательский центр УрО РАН, 620142, Россия, г. Екатеринбург, ул. Белинского, д. 112, корп. A, e-mail: uyniisk@mail.ru.

2. Глаз Николай Владимирович, кандидат сельскохозяйственных наук, старший научный сотрудник отдела садоводства, Уральский федеральный аграрный научно-исследовательский центр УрО PAН, 620142, Россия, г. Екатеринбург, ул. Белинского, д. 112, корп. A, e-mail: kartofel_chel@mail.ru.

Южно-Уральский научно-исследовательский институт садоводства и картофелеводства - филиал ФГБНУ УрФАНИЦ УрО РАН в 20162018 гг. провел исследования по совершенствованию технологии производства саженцев груши с закрытой корневой системой. Изучено влияние состава почвогрунта на фотосинтетическую активность листового аппарата, вегетативный прирост и диаметр штамба саженцев груши при выращивании в контейнерах. Установлено, что введение в состав почвогрунта перегноя не влияет на качество посадочного материала. Совместное применение Базакота и гидрогеля в условиях стабильного обеспечения влагой нецелесообразно. Оптимальным вариантом для выращивания саженцев груши в малообъемных контейнерах оказался почвогрунт, состоящий из почвы и переходного торфа в соотношении $4: 1$ с добавлением удобрения длительного действия Базакот 6М. Применение Базакота (5 г/л) в среднем за 3 года увеличивало длину вегетативного прироста на 36,4 \%, площадь листьев - на $51,1 \%$, диаметр штамба - на 52,2 \%, выход товарных саженцев - в 3,2 раза по сравнению с контролем. Применение гидрогеля Аквасин сопровождалось двукратным увеличением выхода товарных саженцев груши по сравнению с контролем (в среднем за 2017-2018 гг.) - с 22,3 до 44,6 \%. Наибольшая рентабельность производства в условиях 2018 г. отмечена в варианте применении удобрения пролонгированного действия Базакот $-103 \%$.

L. Ufimtseva, N. Glaz

\section{IMPROVEMENT OF THE TECHNOLOGY ELEMENTS OF PRODUCTION OF PEAR SEEDLINGS IN CONTAINERS}

\begin{abstract}
Key words: soil mixture; pear; peat; hydrogel; controlled-release fertilizer.
\end{abstract}

\section{Authors' personal details}

1. Ufimtseva Larisa, Candidate of Biological Sciences, Ural Federal Agrarian Scientific Research Centre Ural Branch of the Russian Academy of Sciences, 620142, Ekaterinburg, Belinsky str., 112 A, e-mail: uyniisk @,mail.ru.

2. Glaz Nikolay, Candidate of Agricultural of Sciences, Ural Federal Agrarian Scientific Research Centre Ural Branch of the Russian Academy of Sciences, 620142, Ekaterinburg, Belinsky str., 112 A, e-mail: kartofel_ chel@mail.ru.

The South Ural Research Institute of Horticulture and Potato - a branch of the Ural Federal Agrar- ian Scientific Research Centre, Ural Branch of the Russian Academy of Sciences in 2016-2018 con- 
ducted research on improving the technology of production of pear seedlings with a closed root system. The influence of the soil composition on the photosynthetic activity of the leaf apparatus, the vegetative growth and the diameter of the stem of pear seedlings when grown in containers was studied. It was established that the introduction of humus in the soil does not affect the quality of planting material. The combined use of Bazacot and hydrogel in conditions of stable moisture supply is impractical. The best option for growing pear seedlings in small containers was a soil mixture composed of soil and transitional peat in a ratio of $4: 1$

(c) Уфимцева Л.В., Глаз Н.В. with the addition of long-acting fertilizer Bazakot $6 \mathrm{M}$. The use of Bazakot $(5 \mathrm{~g} / \mathrm{l})$ on average over 3 years increased the length of vegetative growth by $36,4 \%$, leaf area $-51,1 \%$, the diameter of the stem $-52,2 \%$, the yield of marketable seedlings $-3,2$ times compared to control. The use of Aquasin hydrogel was accompanied by a twofold increase in the yield of marketable pear seedlings compared with the control (on average for 2017-2018) - from 22,3 to $44,6 \%$. The highest profitability of production under the conditions of 2018 was noted in the variant of applying Bazakot prolonged-action fertilizer $-103 \%$.

УДК 633.11«321»:631.526.32(470.51)

DOI: $10.31563 / 1684-7628-2020-53-1-44-50$

И.Ш. Фатыхов, Ч.М. Исламова, Е.Ю. Колесникова

\section{ЭКОЛОГИЧЕСКАЯ ПЛАСТИЧНОСТЬ И СТАБИЛЬНОСТЬ СОРТОВ ЯРОВОЙ ПШЕНИЦЫ НА ГОССОРТОУЧАСТКАХ УДМУРТСКОЙ РЕСПУБЛИКИ}

\section{Ключевые слова: яровая пиеница; сорт; урожайность; индекс среды; экологическая пластич- ность и стабильность; стрессоустойчивость.}

Введение. Условия внешней среды оказывают существенное влияние на развитие хозяйственно-ценных признаков и свойств сортов, определяющих их продуктивность. В неблагоприятных почвенно-климатических условиях все большее значение приобретает не только потенциальная продуктивность сортов, но и их экологическая устойчивость. В связи с этим устойчивый рост урожая сельскохозяйственных культур при разнообразии почвенно-климатических условий по зонам страны тесно связан с созданием и внедрением в производство сортов, отличающихся не только потенциально высокой продуктивностью, но и высокой экологической стабильностью и пластичностью [2].

Важнейшим хозяйственно-ценным признаком сорта пшеницы является урожайность, которая характеризует взаимодействие генотипа со средой и сортовых признаков между собой. Формирование урожая является результатом устойчивости возделываемой культуры к изменяющимся в процессе вегетации экологическим условиям среды $[2,3,7]$. Оценка урожайного потенциала сорта и его реакции на изменяющиеся условия выращивания может быть определена только в конкретных агроэкологических условиях. Учёт параметров адаптивности имеет значение и для Среднего Предуралья, где урожайность яровой пшеницы сильно варьирует по годам [1].
Возделывание яровой мягкой пшеницы в Удмуртской Республике ведётся в разнообразных абиотических условиях. Сорта яровой пшеницы даже в благоприятных зонах их возделывания не в полной мере проявляют свой генетически обусловленный потенциал [6]. Стрессовые метеорологические и погодные условия объективные факторы природы, их нельзя изменить и нужно лишь учитывать при размещении посевов и подборе сортов возделываемой культуры. Целесообразно возделывать не только сорта, имеющие очень высокий потенциал продуктивности посевов, но и сорта, формирующие стабильную урожайность зерна [10]. В условиях Среднего Предуралья достаточно полно изучена реакция на абиотические факторы зерновых культур [1, 9-13], льна-долгунца [8]. В связи с этим была проведена оценка параметров экологической пластичности и стабильности 10 сортов яровой пшеницы, включенных в Государственный реестр селекционных достижений и допущенных к использованию по Удмуртской Республике: Горноуральская, Иргина, Красноуфимская, Омская 36, Свеча, Симбирцит, Черноземноуральская 2, Экада 109, - и сорта Тулайловская Надежда, включенного в Государственный реестр селекционных достижений, допущенных к использованию по Волго-Вятскому региону [9].

Цель исследований: оценить адаптивные свойства сортов яровой пшеницы на госсортоучастках Удмуртской Республики. 